\title{
A Note on Price Asymmetry Using a Monetary Model
}

\author{
Pablo L. Schiaffino1, Juan Pablo Pinasco² \\ ${ }^{1}$ Facultad de Ciencias Económicas, Universidad de Palermo, Buenos Aires, Argentina \\ ${ }^{2}$ Facultad de Ciencias Exactas, Universidad de Buenos Aires, Buenos Aires, Argentina \\ Email: plschiaffino@gmail.com
}

Received 7 August 2014; revised 2 September 2014; accepted 8 October 2014

Copyright (C) 2014 by authors and Scientific Research Publishing Inc.

This work is licensed under the Creative Commons Attribution International License (CC BY).

http://creativecommons.org/licenses/by/4.0/

(c) (i) Open Access

\begin{abstract}
In this paper we present a macroeconomic foundation of downward money price inflexibility based on classical Monetary Economics. We show that under the principle of risk aversion and the neutral money axiom, our model derives an endogenous asymmetric price response as prices adjust more rapidly when they go upward than downward. This asymmetry does not disappear; on the contrary, it is increasing in time.
\end{abstract}

\section{Keywords}

Price Asymmetry, Monetary Model, Sticky Prices, Classical Economics

\section{Introduction}

The literature of asymmetrical price adjustment, both theoretical and empirical, is large ([1] who offer an extensive comprehensive survey). For modern new Keynesian macro, the whole point was analytically to develop microfoundations to justify the existence of price asymmetry or sticky prices. Others theoretical models combined this microeconomic foundation with the strategic interaction factor in order to generate price asymmetries during the adjustment process [2]-[4]. Different kinds of models were built to show up price asymmetries.

In this long list there wasn't, however, a macroeconomic foundation of downward money price inflexibility based on classical Monetary Economics as it is presented in this note. Here, we assume a money demand where agents are risk averse. The conclusion derives an endogenous asymmetric price adjustment as prices adjust more rapidly when they go upward than downward. We analyze price reaction around a neighborhood—at a starting price equilibrium - after we modified the money supply (hence the neutral money axiom holds since prices movements are caused by changes in the quantity of money). This result does not disappear at the second order; on the contrary, it intensifies. 
We work with a standard Monetary model that builds on the same model that J. H. G. Olivera [5] used to study how prices adjust to its equilibrium value, but we reconstruct Olivera's approach in order to analyze how prices behave under changes in the monetary supply. First, we show a first-order effect that the price adjustment process when the quantity of money varies is heterogeneous - a result more or less present in Olivera's model. Second, we show a second-order effect that the initial price asymmetry tends to increase as time goes by a simple but a definitely new innovation. We reconcile this result with some previous empirical and we discuss the essence of this asymmetry arguing that there is an economic intuition behind this result not only a mathematical truth.

\section{The Model}

The starting point is the classical conception that prices fully adjust according to money supply variations:

$$
\dot{p}-F(M, p, e(\dot{p}), V(\dot{p}), e(i), V(i), Y)=0
$$

where $p$ is the price level, $\dot{p}$ is the price time derivative, $M$ is the nominal money supply, $i$ is the real interest rate, $e(\dot{p})$ and $V(\dot{p})$ are the mathematical expectation and the volatility level of the price variation respectively, while $e(i)$ and $V(i)$ are the mathematical expectation and the volatility level of the real interest rate. Finally, $Y$ is the real national income. We define $F$ as the excess money supply function (EMSF), which according to traditional assumptions, varies positively with the nominal money supply.

The EMSF also varies negatively with the price level and positively with expected prices and price volatility. These two assumptions typically capture the reaction of money demand under expected price change and its corresponding volatility. From now on, we concentrate on money variations and its impact over the price dynamic adjustment; hence we assume that $i$ and $Y$ are fixed and remain constant over time.

- Proposition 1: Suppose that $\dot{p}=e(\dot{p})$ and $V(\dot{p})$ is a strict increasing function of $|e(\dot{p})|$. Then, if $\frac{\mathrm{d} F}{\mathrm{~d} p}<0 ; \frac{\mathrm{d} F}{\mathrm{~d} e(\dot{p})}>0 ; \frac{\mathrm{d} F}{\mathrm{~d} V(\dot{p})}>0 ; \frac{\mathrm{d} F}{\mathrm{~d} M}>0$; the immediate price reaction is asymmetrically under changes in the quantity of money.

Proof. Recall we assume that $i$ and $Y$ are fixed and remain constant over time-hence, we can eliminate from (1) for the simplicity of the exposure. Also, that $\dot{p}=e(\dot{p})$ and $V(\dot{p})$ is a strict increasing function of $|e(\dot{p})|$. Therefore, we can re-write Equation (1) into:

$$
\dot{p}-f(M, p, \dot{p},|e(\dot{p})|)=0
$$

Let's define an equilibrium value for price as $\left(p^{*}, \dot{p}^{*},\left|\dot{p}^{*}\right|\right)$. Initially, the system is in equilibrium and the quantity of money at this point is $M^{*}$. We are interested to analyze the immediate impact of changes in the quantity of money around $p^{*}$, hence we assume that $\dot{p}^{*}=\left|\dot{p}^{*}\right|=0$ to simplify. The corresponding Taylor approximation of Equation (2) can be expressed as:

$$
\dot{p}=a\left(M-M^{*}\right)+b\left(p-p^{*}\right)+c \dot{p}+d|\dot{p}|
$$

where $a=\frac{\mathrm{d} f}{\mathrm{~d} M} ; b=\frac{\mathrm{d} f}{\mathrm{~d} p} ; c=\frac{\mathrm{d} f}{\mathrm{~d} \dot{p}} ; d=\frac{\mathrm{d} f}{\mathrm{~d}|\dot{p}|} \quad a, c$ and $d$ are positive constants while $b$ is a negative constant. Notice that the sign that accompanies the term $d|\dot{p}|$ eventually depends on the sign of $\dot{p}$ as we show in the next lines ${ }^{1}$. Equation (3) can be re-written as:

$$
(1-c) \dot{p} \mp d \dot{p}=a\left(M-M^{*}\right)+b\left(p-p^{*}\right)
$$

Or,

$$
\dot{p}=\frac{a\left(M-M^{*}\right)+b\left(p-p^{*}\right)}{(1-c \mp d)}
$$

${ }^{1}$ The final sing over $d|\dot{p}|$ depends on the value of the module. That is, $|\dot{p}|=\left\{\begin{array}{ll}-\dot{p}, & \mid \dot{p}<0 \\ \dot{p}, & \mid \dot{p}>0\end{array}\right.$. 
If prices are initially at equilibrium $\left(p=p^{*}\right)$, any movement in prices will be given by changes in the quantity of money supply. From here, two cases arise. The case when $M>M^{*}$, where it holds that $\dot{p}>0$ - recall that $\frac{\mathrm{d} F}{\mathrm{~d} M}>0$ - and therefore $|\dot{p}|=\dot{p}$. Then,

$$
\dot{p}=\frac{a\left(M-M^{*}\right)}{(1-c-d)}
$$

Conversely, when $M<M^{*}$ it holds that $\dot{p}<0$ and $|\dot{p}|=-\dot{p}$ :

$$
\dot{p}=\frac{a\left(M-M^{*}\right)}{(1-c+d)}
$$

From Equations (3.3) and (3.4), it is immediately inferred that upward price adjustment is more rapid than downward price adjustment when the quantity of money deviates from its equilibrium value.

- Proposition 2: Suppose that the same assumptions of Proposition 1 hold. Then, the price asymmetry stated in Proposition 1 is increasing in time.

Proof. The corresponding Taylor series for price at $t$ at some $t=t_{0}$ is given by:

$$
p=p_{t=0}+\dot{p}_{t=0}\left(t-t_{0}\right)+\ddot{p}_{t=0}\left(t-t_{0}\right)^{2}
$$

where at $t_{0}$ the price level is in equilibrium and equal to $p_{t=0}=p^{*}$. Equation (4) shows that the curvature of Equation (4) depends, among other things, on the value of $\ddot{p}_{t=0}$ (see below Figure 1). Let's differentiate Equation (3) in order to get the second order time derivative at $t_{0}$ :

$$
\ddot{p}=\ddot{p}_{t=0}=a \dot{M}+b \dot{p}+c \ddot{p}+d|\dot{p}|
$$

where $a=\frac{\mathrm{d} f}{\mathrm{~d} M} ; \quad b=\frac{\mathrm{d} f}{\mathrm{~d} p} ; c=\frac{\mathrm{d} f}{\mathrm{~d} \dot{p}} ; d=\frac{\mathrm{d} f}{\mathrm{~d}|\dot{p}|}$ are the same constants as in Proposition 1. Similarly, the sign that accompanies the term $d|\dot{p}|$ eventually depends on the sign of $|\dot{p}|$ and therefore, Equation (5) can be re-written using the respective parameters signs as:

$$
\ddot{p}(1-c \mp d)=a \dot{M}+b \dot{p}
$$

From here, two cases arise. The case when $\dot{M}>0$, where it holds that $\dot{p}>0$ - recall that $\frac{\mathrm{d} F}{\mathrm{~d} M}>0$-and therefore $|\dot{\dot{p}}|=\ddot{p}$. Then,

$$
\ddot{p}=\frac{a \dot{M}+b \dot{p}}{(1-c-d)}
$$

Conversely, when $\dot{M}<0$ it holds that $\dot{p}<0$ and $|\dot{\dot{p}}|=-\ddot{p}$ :

$$
\ddot{p}=\frac{a \dot{M}+b \dot{p}}{(1-c+d)}
$$

Equations (5.1) and (5.2) shows that the initial price asymmetry under changes in the quantity of money (Proposition 1) not only persists as time goes by, it also increase its magnitude when the quantity of money deviates from its equilibrium value. Propositions 1 and 2 are resumed in Figure 1.

\section{Discussion of Propositions 1 \& 2}

This subsection discusses briefly previous results. The logical economic mechanisms operating behind the price asymmetry are 1) the neutral money axiom; 2) the liquidity preference and how does it relates to the risk averse effect. In the first case, we use this fundamental building block theory in order to work over a logical deduction that follows from the neutral money axiom as the raison of price movements. On the second case, the liquidity 


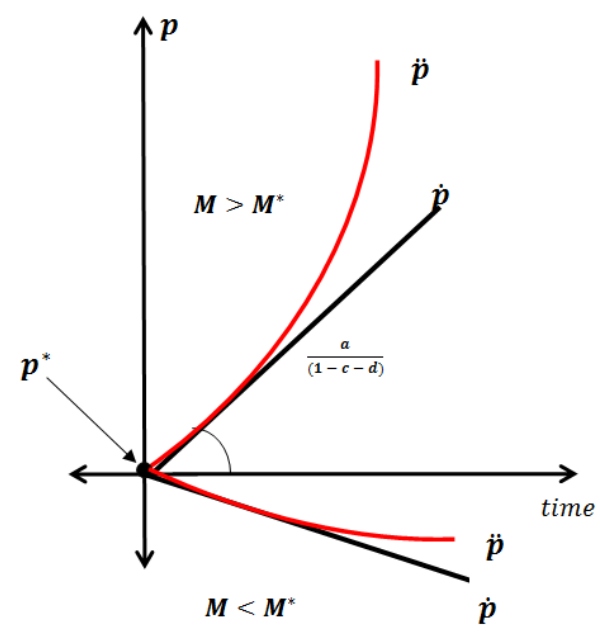

Figure 1. Price dynamics under changes in the quantity of money, featuring Propositions $1 \& 2$.

preference and its relation with volatility simply suggest that when the volatility of prices goes up, even in inflation or deflation, risk-averse attitude implies a decrease in the demand for money, increasing the EMSF.

Altogether the result is described as follows. Money functions as a reserve of value and monetary actions have a quicker impact over prices compare with monetary contractions. This can be explained due to the combination of the risk averse effect $\left(\frac{\mathrm{d} F}{\mathrm{~d}|\dot{p}|}\right)$ and the inflation/deflation process: when money expands and inflation occurs, the increase in the value of $M$ rises the value of the price volatility; as volatility is rising, an increasing value for the excess money supply function (EMSF) push prices forward reinforcing the initial inflationary process caused initially due to the monetary expansion. When money decreases and deflation occurs, the reduction in the value of $M$ increases price volatility and the money excess supply function. The increase in the EMSF will generate a price increase (inflation), which will offset part of the initial deflationary process due to the initial monetary contraction and, therefore, reducing volatility. For all this, positive monetary shocks will have a greater impact over prices compare with negative ones, likewise prices will react more rapidly in the upward case compare with the downward.

\section{Conclusion}

This theoretical result resembles what Brandt and Wang [6] show empirically: the volatility of inflation is time-varying and tends to be high when the level of inflation is high; therefore, deflation periods will possess a lower volatility level compared to those characterized by high inflation. Since the mechanical process underling price reactions are quite different in the upward adjustment case $(\dot{p}>0)$ compared to the downward case $(\dot{p}<0)$, under changes in the quantity of money, an asymmetry in price reactions should be expected when the quantity of money varies. This asymmetry is increasing in time, as Proposition 2 shows.

\section{Acknowledgements}

We thank Universidad de Palermo, Facultad de Ciencias Economicas for available funding. Pablo Schiaffino wishes to thank J. H.G Olivera. Much of the spirit of this note is based on the conversations that the two academics hold over this particularly issue between 2011 and 2013.

\section{References}

[1] Meyer, J. and Cramon-Taubadel, S. (2004) Asymmetric Price Transmission: A Survey. Journal of Agricultural Economics, 55, 581-611. http://dx.doi.org/10.1111/j.1477-9552.2004.tb00116.x

[2] Maskin, E. and Tirole, J. (1988) A Theory of Dynamic Oligopoly, II: Price Competition, Kinked Demand Curves, and 
Edgeworth Cycles. Econometrica: Journal of the Econometric Society, 56, 571-599. http://dx.doi.org/10.2307/1911701

[3] Sen, D. (2004) The Kinked Demand Curve Revisited. Economics Letters, 84, 99-105. http://dx.doi.org/10.1016/j.econlet.2004.01.005

[4] Schiaffino, P. (2010) A Theory of Kinked Demand Curve: Dynamic Game Theory and Price Rigidity. Anales de la Asociación Argentina de Economía Política. http://www.aaep.org.ar/anales/works/works2010/schiaffino.pdf

[5] Olivera, J.H. (1984) Note sur l'inflexibilité des prix á la baisse. Revue d'économie politique, 94, 808-810.

[6] Brandt, M.W. and Wang, K.Q. (2003) Time-Varying Risk Aversion and Unexpected Inflation. Journal of Monetary Economics, 50, 1457-1498. http://dx.doi.org/10.1016/j.econlet.2004.01.005 
Scientific Research Publishing (SCIRP) is one of the largest Open Access journal publishers. It is currently publishing more than 200 open access, online, peer-reviewed journals covering a wide range of academic disciplines. SCIRP serves the worldwide academic communities and contributes to the progress and application of science with its publication.

Other selected journals from SCIRP are listed as below. Submit your manuscript to us via either submit@scirp.org or Online Submission Portal.
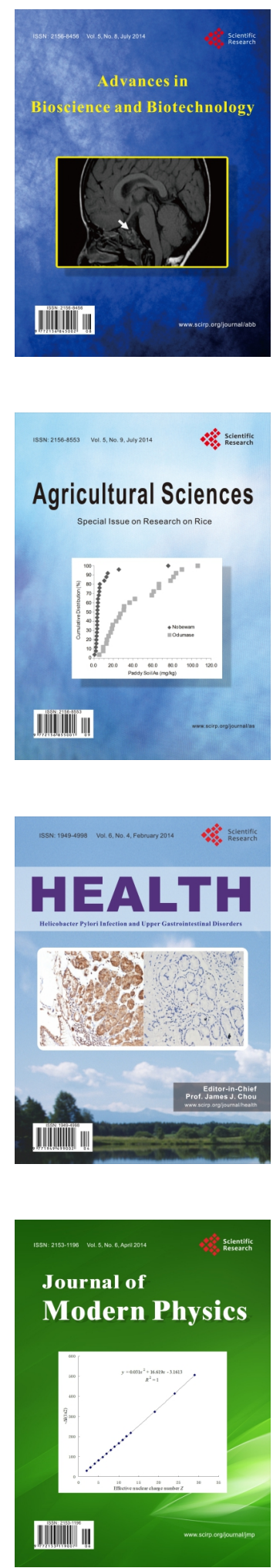
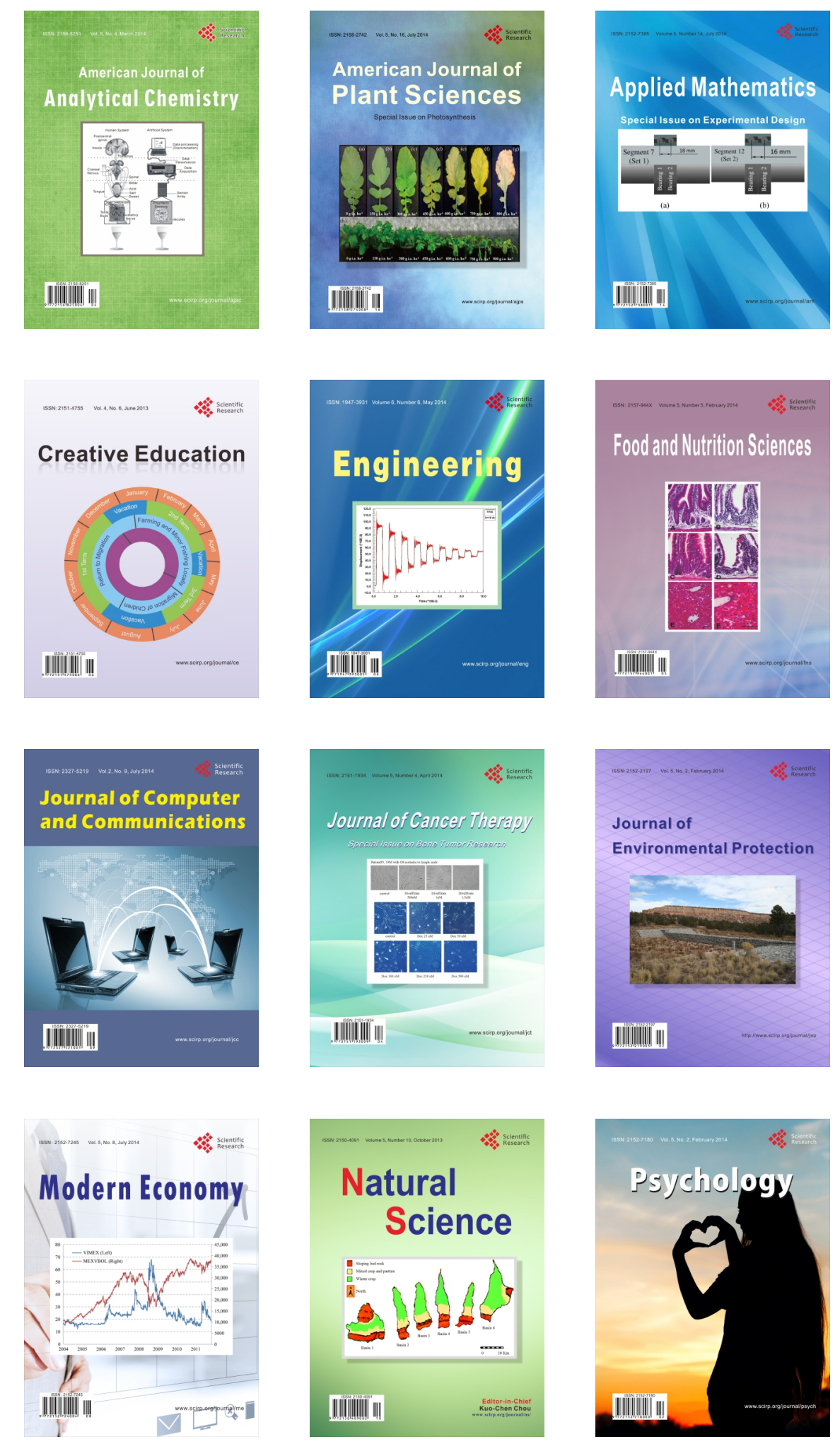